\title{
SOCIO-DEMOGRAPHIC INSIGHTS INTO SOUTH AFRICAN STUDENT DRINKING BEHAVIOUR
}

\author{
B. W. Lategan* \\ Department of Business Management \\ e-mail: bwl@sun.ac.za \\ R. du Preez* \\ Department of Industrial Psychology \\ e-mail: rdp@sun.ac.za \\ C. D. Pentz ${ }^{*}$ \\ Department of Business Management \\ e-mail: cdpentz@sun.ac.za
}

*Stellenbosch University

Stellenbosch, South Africa

\section{ABSTRACT}

Hazardous and harmful drinking is on the rise among adolescents and young adults and has been classified as a major health problem. University students are a subgroup of young adults that are characterised by more frequent and even more dangerous drinking behaviours than their nonstudent peers, and new intervention approaches are needed to foster behavioural change. The purpose of this study is to investigate the drinking behaviour and socio-demographic profile of a cohort of South African university students and propose future research avenues to address student drinking behaviour. Ex post facto survey data was collected by means of a questionnaire including the Alcohol Use Disorder Identification Test (AUDIT) and a demographic section. Data was gathered from university students $(n=474)$ from a single campus within South Africa. Data analyses included descriptive statistics, reliability analysis, independent sample t-tests and oneway ANOVAs. Results indicate significant differences in drinking behaviour for gender groups; age; level of disposable income; type of beverage consumed, binge drinking, level and frequency of consumption. The findings have implications for higher education management, public health authorities, and academia, and provide valuable insights into the socio-demographic profile and drinking behaviour of a cohort of university students. The findings serve as a foundation for future research into the development of a persuasive communications strategy (educational and prevention campaigns) that could foster much needed behavioural change.

Keywords: Drinking behaviour, South African student drinking, income, gender, age, university students 


\section{INTRODUCTION}

This article is the second by the authors to address student drinking behaviour in a South African context. In the first article (Du Preez, Pentz and Lategan 2016) the role of drinking behaviour, alcohol motives, and outcome expectancies were investigated and findings indicated that further insights into the reasons why students consume alcohol, should be sought. This research responds to the call for further insights and seeks to find further clarification on the role of socio-demographic variables in student drinking behaviour.

Before and after college, drinking oneself into a state of blissful oblivion requires a degree of secrecy. In high school, it needs to be hidden from parents. In the working world, it must be downplayed to bosses, or concerned friends, or lovers.

But in college, we can wear our alcohol abuse as proudly as our university sweatshirts; the two concepts are virtually synonymous. (Koren Zailckas, American writer and author of Smashed 2006, 111)

Alcohol abuse has widespread negative social consequences. Globally, alcohol is the third largest risk factor for disease and disability, and the eighth largest risk factor for death (Global Status Report on Alcohol and Health 2014). In 2000, an estimated 7.0 per cent of all deaths and 7.1 per cent of the burden of disease in South Africa were attributed to alcohol, which figures are significantly higher than the global averages (Schneider et al. 2007). South Africa has also been identified by the World Health Organisation (WHO) as a country with high per capita alcohol consumption coupled with binge and harmful drinking patterns (Global Status Report on Alcohol and Health 2011; 2014) suggesting that South Africa has a serious alcohol problem. To compound the problem, young South African adults seem to be more prone to high levels of alcohol consumption and alcohol-related problems than their global peers (Peltzer, Davids and Njuho 2011).

On a global scale, it appears that hazardous and harmful drinking patterns, such as drinking to intoxication and binge drinking, are on the rise among adolescents and young adults (Jernigan 2001). South Africa faces similar challenges where Peltzer et al. (2011) identified young adults as having the highest levels of binge, hazardous, and harmful drinking patterns. Consequently, drinking among young adults is of great concern to the South African public health community and drastic policy changes (e.g. a ban on alcohol advertising and a zero limit for drinking and driving) are being proposed to address this drinking problem (Germishuys 2015; South African Press Association 2013).

University students, a subgroup of young adults, are characterised by heavier, more frequent, and even more dangerous drinking patterns than their non-student peers (Kypri, Cronin and Wright 2005; Slutske et al. 2004). Alcohol consumption and excessive drinking are 
often perceived as 'normal' and part of the university experience, but the drinking behaviour of university students has in fact been classified as a major health problem. Although the drinking behaviour of North American university students is well documented (Hingson, Zha and Weitzman 2009), little is known about the drinking behaviour of South African university students, which means the drinking behaviour of this cohort is not well understood (Young and De Klerk 2008). As a result, alcohol abuse awareness and prevention campaigns targeted towards South African university students have not necessarily been informed by context specific scientific findings, nor have they led to the intended behavioural change.

Most persuasion messages focus on the negative effects of drinking and not on the positive effects of not drinking or only moderate alcohol usage. Furthermore, messages are often framed within the directive authoritarian frame that is high in demandingness (control) and low in responsiveness (support and affect) (see the seminal work of Maccoby and Martin 1983) for e.g. 'Don't drink' and 'Alcohol kills'. These messages lack the necessary empowerment to motivate a change in alcohol usage behaviour together with a supportive and affective message that fosters both control and responsiveness (authoritative). Paiva, Bastos and Ronzani (2012) report in their study on the alcohol consumption of Brazilian adolescents that maternal, authoritative and authoritarian parenting styles were directly related to alcohol intake. They urge researchers to take a multi-disciplinary view in preventative strategies and for all stakeholders to share in the responsibility of prevention and educational programme development.

Thus, the development of a better understanding with regard to the drinking behaviour of university students is essential to address the drinking-related problems that this cohort is experiencing. The complexity of the phenomenological network of variables that influence drinking behaviour was recognised by Lategan (2015), and the influence of alcohol motives and outcome expectancies on the drinking behaviour of South African university students has been reported on previously (Du Preez, Pentz and Lategan 2016; Lategan 2015). Still, very little research exists on the drinking behaviour of university students in South Africa (Young and De Klerk 2008).

Due to the dearth of existing knowledge, the purpose of this research article is to gain further insight into the drinking behaviour of university students in South Africa by investigating specifically their drinking behaviour and socio-demographic profile (with emphasis on gender, age and disposable income) and to make recommendations (drawing from various knowledge fields) towards the development of persuasive communications strategies (educational and prevention campaigns) within a social marketing sphere that would address 
the negative consequences that this cohort experience as a result of excessive alcohol consumption.

\section{DRINKING BEHAVIOUR}

Due to the adverse health and social consequences caused by alcohol abuse, drinking behaviour is a well-researched topic that has been studied among diverse population groups including adolescents, university students and various non-student populations. The existing research represents views from multiple disciplines including marketing, consumer behaviour, psychology, and the health sciences (e.g. Du Preez, Pentz and Lategan 2016; Elgar et al. 2005; Peltzer, Naidoo, Matseke and Zuma 2011; Peltzer et al. 2011; Young and De Klerk 2008). The World Health Organisation (WHO) has functioned as a repository of global alcohol consumption statistics, using diverse research studies to develop individual country profiles and release global alcohol reports (e.g. Global Status Report on Alcohol and Health 2011; 2014). The WHO developed a measurement instrument for the identification of dangerous drinking patterns, alcohol-related problems, and alcohol dependency, named the Alcohol Use Disorder Identification Test (AUDIT). Using the AUDIT, the WHO identified and defined five primary patterns of alcohol consumption along the continuum of safe to dangerous drinking by taking into account the levels and frequency of alcohol consumption in conjunction with the consequences of alcohol consumption. These five patterns are: safe drinking, hazardous drinking, harmful drinking, binge drinking, and alcohol dependence (Babor et al. 2001).

Safe drinking signifies a pattern of alcohol consumption that does not result in the increase of risk, or manifestation of adverse physical, psychological, or social consequences to the user or significant others. Hazardous drinking is defined as a pattern of alcohol consumption that increases the risk of harmful consequences for the user or others without having yet caused any alcohol-related harm (Babor et al. 2001). Harmful drinking is defined by the ICD-10 Classification of Mental and Behavioural Disorders as a pattern of alcohol consumption that results in negative consequences to physical and mental health without meeting the full clinical criteria of alcohol dependence. Alcohol dependent drinking is a pattern of alcohol consumption characterised by high-risk drinking and moderate or severe dependence on alcohol. The ICD10 defines alcohol dependence as a cluster of symptoms that include a strong desire or sense of compulsion to use alcohol, impaired control over alcohol use, physiological withdrawal when alcohol consumption is ceased or reduced, greater tolerance of alcohol, preoccupation with alcohol, and persistence with drinking, despite clear evidence of harmful consequences (The ICD-10 Classification of Mental and Behavioural Disorders 1992). These individuals are 
almost certainly dependent on alcohol and an intervention is recommended in an attempt to break their dangerous drinking patterns (Babor et al. 2001). The WHO does not provide an explicit definition of binge drinking, resulting in a range of definitions being present in the literature (Gill 2002). For the purpose of this study binge drinking is defined as having had six or more standard alcoholic drinks in one sitting in the last 30 days.

\section{Drinking behaviour in South Africa}

Peltzer et al. (2011) report that among a sample of South African citizens, 27.7 per cent were indicated to be current drinkers. Of the total sample, 9 per cent indicated hazardous and more dangerous levels of drinking and 9.6 per cent reported binge drinking behaviour. However, among current drinkers, the occurrence of hazardous and more dangerous levels of drinking was 31.5 per cent. Prior to the work of Peltzer et al. (2011), several population surveys were conducted that provide evidence of drinking patterns at the individual level, including two Demographic and Health Surveys (DHS) of 1998 and 2003, the South Africa World Health Survey (WHS) of 2003, the South African Stress and Health (SASH) survey of 2002-2004, and the South African national HIV prevalence, Behaviour and Communication Survey (SABSSM II) of 2005 (Peltzer et al. 2011; Peltzer and Ramlagan 2009; Van Heerden et al. 2009).

Current drinking rates as measured by alcohol consumed in the past week or past month (depending on survey) were found to be similar across different surveys, ranging from 20 per cent-30 per cent (28\% DHS 1998; 20\% DHS 2003; 29.9\% WHS 2003; and 24.5\% SABSSM II 2005), with significantly more men reporting to be current drinkers than women. Binge drinking defined as drinking five or more alcoholic drinks on the same occasion on at least 1 day in the past 30 days or 7 days (depending on survey) was reported among 7.4 per cent of participants in SABSSM II 2005 and among 10.8 per cent in WHS 2003. Hazardous or harmful drinking was exhibited by 17.2 per cent of the sample population in DHS 1998, and 13.7 per cent in DHS 2003 (measured with the CAGE instrument), while 6.2 per cent of participants in SABSSM II 2005 and 5.3 per cent of educators in 2004 reported hazardous or harmful drinking patterns as measured using the AUDIT instrument. The only survey conducted among adolescents, the Youth Risk and Behaviour Survey, was conducted in 2002 and reported that 31.8 per cent of students (78.7\% were between the ages of 14 and 18 years) were current alcohol users, while 23.0 per cent exhibited binge drinking behaviour (Peltzer et al. 2011).

Using a sample of South African university students from a single campus, Young and De Klerk (2008) observed that 49.1 per cent of respondents reported safe levels of drinking with 33 per cent reporting hazardous drinking patterns, 9.6 per cent alcohol dependent levels of 
consumption and lastly 8.3 per cent exhibiting harmful drinking patterns. A total average AUDIT score of 8.94 was reported for the 2007 sample and 8.84 for the 2008 sample, suggesting that the average student exhibits hazardous patterns of drinking (identified by an AUDIT score of 8 or higher) across both years. Comparing the results of Peltzer et al. (2011) and other population surveys with the findings of Young and De Klerk (2008) suggests that students exhibit more dangerous drinking patterns than non-students, which is consistent with previous literature (Kypri, Cronin and Wright 2005; Slutske et al. 2004).

\section{SOCIO-DEMOGRAPHIC VARIABLES}

Research suggests that numerous socio-demographic variables influence drinking behaviour. The complexity of the nomological network of variables is acknowledged; however the focus of this article is on gender, age and disposable income as the existing literature reports said variables as significant predictors of drinking behaviour (Ahlström, Bloomfield and Knibbe 2001; Corbin, Vaughan and Fromme 2008; Obot 2006; Peltzer and Ramlagan 2009).

\section{Gender}

A variety of studies suggest that a clear association exists between gender and drinking behaviour (Ahlström, Bloomfield and Knibbe 2001; Engs and Hanson 1990; Holmila and Raitasalo 2005; Wilsnack et al. 2000). Generally, men consume alcohol more frequently and in larger quantities than women and are more likely to engage in binge drinking, hazardous drinking and harmful drinking. Men are also more likely to be current drinkers while women are more likely to abstain from alcohol consumption (El Ansari, Sebena and Stock 2013; Global Status Report on Alcohol and Health 2011; Peltzer et al. 2011; Wilsnack et al. 2000; Wilsnack et al. 2009). Studies that focused on young adults have indicated that young men tend to drink more frequently, in larger quantities, and with more problematic consequences than young women do (Powell, Faden and Wing 2007; Wallace et al. 2003). A UK survey involving ten universities, for example, reported that 61 per cent of male students and 48 per cent of female students exceeded the safe drinking limits (Webb et al. 1996). In a South African context, male university students exhibited significantly higher levels of hazardous, harmful and dependent drinking patterns while females reported higher levels of safe alcohol consumption (Young and De Klerk 2009). It can, therefore, be posited that differences exist between the drinking behaviour of male and female South African university students by considering the following hypotheses: 
$\mathrm{H}_{1(\mathrm{~A}) \text { : }}$ Male university students consume alcohol more frequently than female university students

$\mathrm{H}_{1(\mathrm{~B}):}$ Male university students consume higher levels of alcohol (i.e. more) than female university students

$\mathrm{H}_{1(\mathrm{C}) \text { : }}$ Male university students are more likely to engage in binge drinking than female university students

$\mathrm{H}_{1(\mathrm{D}):}$ : Male university students are more likely to engage in hazardous, harmful and dependent drinking than female university students

\section{Age}

Age is a major determinant of drinking behaviour and has an influence on the quantity of alcohol consumption as well as the pattern of drinking (Global Status Report on Alcohol and Health 2014; Peltzer et al. 2011). Alcohol consumption tends to increase throughout adolescence and young adulthood (Johnston et al. 2009; Schulenberg and Maggs 2002), spiking during the years that students spend at university (Corbin, Vaughan and Fromme 2008). This is usually the time directly after individuals have gained freedom from their parents and the school system. In a South African context, Peltzer et al. 2011 observed that binge, hazardous and harmful drinking sharply increases from adolescence (15-19) into young adulthood (20-34), spiking during this life stage. A slow decrease is evident as these individuals progress through middle age, reaching the lowest point over the age of 65 .

University students seem to consume significantly more alcohol in their first year at university than in their second and third years of studying (Bewick et al. 2008), suggesting that age might influence drinking behaviour among university students. Therefore it can be posited that:

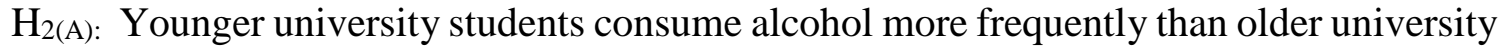
students

$\mathrm{H}_{2(\mathrm{~B}):}$ Younger university students consume higher levels of alcohol (i.e. more) than older university students

$\mathrm{H}_{2(\mathrm{C}):}$ Younger university students are more likely to engage in binge drinking than older university students

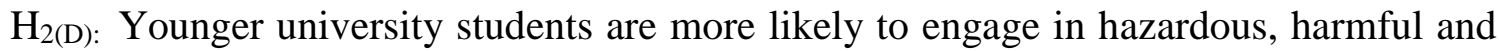
dependent drinking than older university students 


\section{Income}

The dominant school of thought in the literature proposes that as income rises, so does frequency of alcohol consumption, level of consumption and alcohol-related problems (Keyes and Hasin 2008; Obot 2006; Peltzer et al. 2011). Keyes and Hasin (2008) for example report income as a significant positive predictor of drinking after driving and drinking while driving, which can be regarded as manifestations of hazardous drinking. Peltzer et al. (2011) report that among a sample of South Africans, individuals who earn between R12 000 and R48 000 per year exhibit significantly higher levels of binge, hazardous and harmful drinking patterns than individuals who earn less than R12 000 and more than R48 000 per year. It appears that individuals with greater levels of income (more than R48 000 per year), exhibit the highest levels of current drinking but the lowest levels of hazardous and harmful drinking (Peltzer et al. 2011). Casswell, Pledger and Hooper (2003) concur and report that individuals with higher levels of income drink more often than individuals with lower levels of income. However, university students do not earn salaries and disposable income the same way adults do, therefore the findings cannot directly be applied to university students. Yet, evidence suggests that university students in South Africa receive a comparable income to that of working adults (sources of income include, for example, pocket money, bursaries, part-time jobs) (Solomon 2013). It can, therefore, be argued that higher levels of disposable income are related to higher levels of alcohol consumption and consequently alcohol-related problems among university students. Thus, it is hypothesised that disposable income positively influences the drinking behaviour of university students.

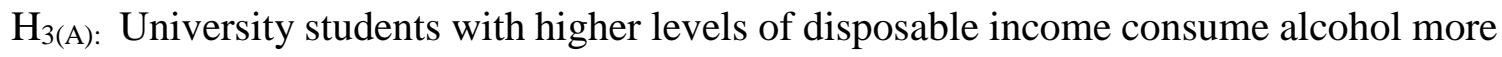
frequently than university students with lower levels of disposable income

$\mathrm{H}_{3(\mathrm{~B}):}$ University students with higher levels of disposable income consume higher levels of alcohol (i.e. more) than university students with lower levels of disposable income

$\mathrm{H}_{3(\mathrm{C}):}$ University students with higher levels of disposable income are more likely to engage in binge drinking than university students with lower levels of disposable income

$\mathrm{H}_{3(\mathrm{D}):}$ University students with higher levels of disposable income are more likely to engage in hazardous, harmful and dependent drinking than university students with lower levels of disposable income 


\section{Type of beverage}

Associations have been observed between the alcoholic beverage preferences of drinkers and various drinking-related outcomes, including frequency and level of consumption, drinking patterns, risk-taking behaviour and personal characteristics. Preferences for types of alcoholic beverages in the literature vary greatly among samples of drinkers investigated. Historically alcohol has been divided into four categories in a South African context, namely beer, wine, ciders (ready-to-drink beverages) and spirits (Opperman 2010).

Among a sample of US high school adolescents, Siegel et al. (2011) found that spirits was the alcoholic beverage of choice for 43.8 per cent of students followed by beer (19.2\%) and ciders (17.4\%), with a very low preference for wine (3.7\%) or wine coolers (3.4\%). Students with a clear preference for spirits and beer exhibited higher frequency of alcohol consumption and binge drinking as well as a tendency to drive after drinking, than students who preferred other beverages. Alcoholic beverage preference was also found to be associated with other risky behaviours, with cigarette and drug use associated with an increased preference for spirits and beer. This was less evident for those who preferred ciders, wine, and wine coolers (Siegel et al. 2011). Using longitudinal data, Jensen et al. (2002) concur that moderate drinkers who prefer beer are more likely to become heavy or excessive drinkers than individuals who prefer wine. It was also reported that moderately drinking men who included wine in their weekly alcohol portfolio showed decreased risk of heavy and excessive alcohol consumption (Jensen et al. 2002).

Barefoot et al. (2002) observed that out of the portion of the US sample that were drinkers, 39 per cent preferred wine followed by beer (35\%) and spirits (17\%), with 9 per cent of drinkers having no clear beverage preference. Significant gender differences were also observed, with men exhibiting a higher preference for beer while women showed a clear preference for wine (Barefoot et al. 2002). Contradictorily, among a sample of regular drinkers Gaziano et al. (1999) found that more than half of participants (51\%) had no clear preference for a specific alcoholic beverage followed by 25 per cent preferring spirits, 14 per cent indicating a preference for beer and 10 per cent being wine drinkers. Individuals who preferred spirits indicated the highest level of alcohol consumption closely followed by beer drinkers and those with no clear preference. Wine consumers exhibited significantly lower levels of alcohol consumption than the rest of the sample (Gaziano et al. 1999).

In a US study, Klatsky, Armstrong and Kipp (1990) reported that 49.3 per cent showed no clear preference for a specific alcoholic beverage followed by 25.9 per cent preferring wine, 13.4 per cent showing a preference for beer and 11.4 per cent selecting spirits as their beverage 
of choice. Individuals who preferred wine were likely to be women, young or middle-aged, non-smokers and better educated. Individuals who preferred spirits were likely to be men, heavier drinkers, middle-aged or older, less educated and afflicted with symptoms or risk factors for major illnesses. Individuals who preferred beer were likely to be young men with the same characteristics as individuals who preferred wine and spirits.

From these studies it is evident that beverage preference has an association with drinking behaviour and that preferences for alcoholic beverages differ significantly across samples. A consistent trend that emerges in the literature is that spirits is associated with the most problematic drinking behaviour. The type of beverage consumed by university students thus forms part of the drinking behaviour variables investigated in the present study and it is hypothesised that the type of alcoholic beverage most often consumed by university students significantly influences their drinking behaviour. Therefore, the following hypotheses are considered:

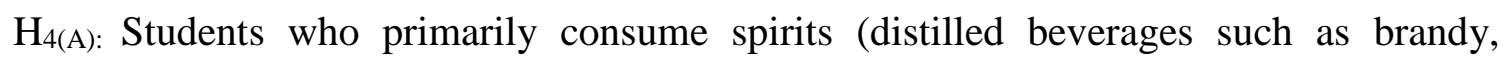
whisky, vodka and gin) consume alcohol more frequently than students who primarily consume other alcoholic beverages

$\mathrm{H}_{4(\mathrm{~B}):}$ Students who primarily consume spirits consume higher levels of alcohol (i.e. more) than students who primarily consume other alcoholic beverages

$\mathrm{H}_{4(\mathrm{C}):}$ Students who primarily consume spirits are more likely to engage in binge drinking than students who primarily consume other alcoholic beverages

$\mathrm{H}_{4(\mathrm{D}) \text { : }}$ Students who primarily consume spirits are more likely to engage in hazardous, harmful and dependent drinking than students who primarily consume other alcoholic beverages

\section{METHODOLOGY}

\section{Research problem}

The research problem is defined as the lack of understanding regarding the drinking behaviour of university students in South Africa and the seeming inability of current persuasive communication strategies to result in much needed behavioural change to remedy the serious alcohol problem South Africa is facing, especially among young adults. Thus, it is the purpose of the present study to contribute to the understanding of the drinking behaviour of university students in South Africa by investigating their drinking behaviour and socio-demographic 
profile.

\section{Sample and data collection}

A convenience sample ( $n=474)$ of South African university students, above the age of 18 who are current consumers of alcohol (consumed alcohol in the past 12 months), participated in this study. Ethical and institutional clearance was obtained and data was collected in classrooms by means of a paper and pencil format questionnaire. Informed consent was obtained from each participant, ensuring voluntary participation, and the goal of the study and possible risks of participation were explained. Anonymity of respondents was ensured by not collecting any identifiable information from respondents.

\section{Measurement instruments}

The Alcohol Use Disorder Identification Test (AUDIT): The AUDIT is a valid and reliable measure of drinking behaviour developed by the WHO with a reported sensitivity of 92 per cent and specificity of 94 per cent in detecting hazardous and harmful alcohol use (Allen et al. 1997; Saunders et al. 1993). The AUDIT has acceptable psychometric properties (reliability) with a Cronbach's alpha score of 0.83, with a range of 0.75 to 0.97 (Reinert and Allen 2007). In the current study Cronbach's alpha scores of 0.832 and 0.736 were reported for the overall AUDIT scale and consumption subscale respectively, suggesting acceptable internal consistency. The AUDIT has been translated into various languages and appears to be valid across cultures, and is widely used in research and clinical settings (Allen et al. 1997; Babor et al. 2001). The AUDIT has also been administered in several studies using university students as respondents (e.g. Andersson et al. 2007; Fleming, Barry and MacDonald 1991; Granville-Chapman, Yu and White 2001; Kypri et al. 2002; McShane and Cunningham 2003; O’Hare and Sherrer 1999; Shields, Guttmannova and Caruso 2004). Consequently, the AUDIT was used as the preferred measure of drinking behaviour in this study.

The AUDIT consists of 10 items with 3 items each on alcohol consumption and alcohol dependence symptoms, and 4 items on problems associated with drinking. Each item has a scoring range from 0 to 4 with a total score that ranges from 0 to 40 , with higher total scores indicating more dangerous drinking. The AUDIT is a useful predictor of drinking patterns and alcohol-related problems, with a score of 8 or higher associated with future alcohol problems. In general, a score between 8 and 15 is associated with hazardous drinking, a score of 16 to 19 is indicative of harmful drinking while a score of 20 or higher suggests alcohol dependence (Babor et al. 2001; Young and De Klerk 2008). 
General questionnaire: A general questionnaire was compiled to include demographic items and questions related to general drinking behaviour (e.g. drinking partners, location of drinking, date and time of drinking, and type of beverage consumed).

\section{Data analysis}

To establish the reliability of the AUDIT measurement instrument among the sample population of university students, Cronbach alpha scores were calculated for the overall AUDIT questionnaire and the consumption subscale. Cronbach alpha scores of 0.7 and higher were deemed acceptable (Nunnally and Bernstein 1994). To investigate the possible differences between male and female university students in the sample population, a series of independent sample t-tests were conducted. To determine if drinking behaviour differs between age groups of university students, whether students with dissimilar levels of disposable income consume alcohol differently, and whether students who prefer differential alcoholic beverages consume alcohol differently, a series of one-way ANOVAs were conducted. Tukey HSD tests were utilised for all post-hoc ANOVA analyses. A 95 per cent confidence interval was used across all techniques of analysis. To determine the effect size of the differences eta squared was calculated and the guidelines proposed by Cohen (1988) were used for interpretation, which are as follows: $0.01=$ small effect, $0.06=$ moderate effect, $0.14=$ large effect.

\section{RESULTS AND DISCUSSION}

\section{Socio-demographic and drinking behaviour profile}

Socio-demographic and drinking behaviour indicators were used in this study to develop a profile of the sample population and to gain deeper insights into the drinking behaviour of university students. Table 1 shows the preferred alcoholic beverages and preferred drinking locations of university students and their relation to drinking behaviour, followed by a discussion on supplementary drinking behaviour indicators. Table 2 contains a representation of the socio-demographic profile of the sample with each variable divided into safe, hazardous, harmful and dependent drinking behaviour.

\section{Drinking partners}

Drinking alcohol is a social activity commonly practised in company, and as expected the vast majority of respondents (89\%) reported consuming alcohol mostly with university friends, while others indicated drinking with working friends (not fellow students) (5\%), parents (2\%) or by themselves (1\%). 
Table 1: Preferred beverage, location and drinking behaviour

\begin{tabular}{|c|c|c|c|c|c|c|c|c|c|c|c|c|}
\hline \multirow{2}{*}{ Characteristics } & \multicolumn{2}{|c|}{ Total } & \multicolumn{2}{|c|}{$\begin{array}{c}\text { Total Audit } \\
\text { score }\end{array}$} & \multicolumn{2}{|c|}{ Safe } & \multicolumn{2}{|c|}{ Hazardous } & \multicolumn{2}{|c|}{ Harmful } & \multicolumn{2}{|c|}{ Dependent } \\
\hline & $\mathrm{N}$ & $\%$ & Mean & SD & $\mathbf{N}$ & $\%$ & $\mathbf{N}$ & $\%$ & $\mathbf{N}$ & $\%$ & $\mathrm{~N}$ & $\%$ \\
\hline \multicolumn{13}{|l|}{ Preferred beverage } \\
\hline Beer & 110 & 24.2 & 12.54 & 6.37 & 25 & 22.7 & 56 & 50.9 & 13 & 11.8 & 16 & 14.5 \\
\hline Cider & 76 & 16.7 & 6.46 & 4.85 & 51 & 67.1 & 21 & 27.6 & 2 & 2.6 & 2 & 2.6 \\
\hline Wine & 159 & 35.0 & 7.4 & 4.8 & 93 & 58.5 & 58 & 36.5 & 5 & 3.1 & 3 & 1.9 \\
\hline Spirits & 109 & 24.0 & 10.82 & 5.83 & 36 & 33.0 & 56 & 51.4 & 8 & 7.3 & 9 & 8.3 \\
\hline \multicolumn{13}{|l|}{ Preferred location } \\
\hline Bar & 133 & 34.6 & 10.53 & 5.72 & 46 & 34.6 & 68 & 51.1 & 10 & 7.5 & 9 & 6.8 \\
\hline Club & 99 & 25.8 & 9.62 & 5.66 & 40 & 40.4 & 47 & 47.5 & 2 & 2.0 & 10 & 10.1 \\
\hline House/apartment & 109 & 28.4 & 9.42 & 6.74 & 52 & 47.7 & 40 & 36.7 & 10 & 9.2 & 7 & 6.4 \\
\hline Restaurant & 43 & 11.2 & 4.58 & 3.49 & 36 & 83.7 & 6 & 14.0 & 1 & 2.3 & 0 & 0.0 \\
\hline
\end{tabular}

\section{Date and time of drinking}

Students reported drinking most heavily over weekends, especially Friday and Saturday nights.

\section{Beverage consumed in social settings}

Students regarded different alcoholic beverages as more appropriate in different social situations resulting in 52 per cent of students preferring to drink wine at home, followed by beer (22\%), ciders (15\%), and spirits (11\%). These percentages are mirrored when drinking at a restaurant. The alcoholic beverage preference changes drastically when the location of consumption changes to bars and clubs. Here, spirits are the preferred drink for 47 per cent of students, followed by ciders (27\%) and beer (20\%). What is noteworthy is that wine consumption in this setting decreases to only 6 per cent.

\section{Drinking behaviour as measured by AUDIT}

Generally, the lower an individual's total AUDIT score, the less that individual tends to drink and the less likely they are to experience alcohol-related problems (Babor et al. 2001). The majority of AUDIT scores (93\%) range from 1 to 19 with an average AUDIT score of 9.35 achieved across the sample. Although seemingly low, taking into account that a maximum of 40 can be achieved, 9.35 is relatively high suggesting that the average university student in this sample consumes alcohol at hazardous levels. This is disconcerting and supports the argument that South Africa has an alcohol problem among its young adult population, particularly 
Table 2: Socio-demographic profile and drinking behaviour

\begin{tabular}{|c|c|c|c|c|c|c|c|c|c|c|c|c|}
\hline \multirow{3}{*}{ Characteristics } & & & & & & & \multicolumn{6}{|c|}{ Drinking behaviour } \\
\hline & \multicolumn{2}{|c|}{ Total } & \multicolumn{2}{|c|}{$\begin{array}{l}\text { Total Audit } \\
\text { score }\end{array}$} & \multicolumn{2}{|c|}{ Safe } & \multicolumn{2}{|c|}{$\begin{array}{c}\text { Hazardou } \\
\text { s }\end{array}$} & \multicolumn{2}{|c|}{ Harmful } & \multicolumn{2}{|c|}{$\begin{array}{c}\text { Dependen } \\
t\end{array}$} \\
\hline & $\mathbf{N}$ & $\%$ & Mean & SD & $\mathbf{N}$ & $\%$ & $\mathbf{N}$ & $\%$ & $\mathbf{N}$ & $\%$ & $\mathbf{N}$ & $\%$ \\
\hline Total & 474 & 100 & 9.35 & 6.02 & 213 & 44.9 & 199 & 42.0 & 30 & 6.3 & 32 & 6.8 \\
\hline \multicolumn{13}{|l|}{ Gender } \\
\hline Male & 200 & 42.2 & 11.67 & 6.47 & 58 & 29.0 & 97 & 48.5 & 20 & 10.0 & 25 & 12.5 \\
\hline Female & 274 & 57.8 & 7.67 & 5.05 & 155 & 56.6 & 102 & 37.2 & 10 & 3.6 & 7 & 2.6 \\
\hline \multicolumn{13}{|l|}{ Age } \\
\hline$<19$ & 61 & 15.4 & 7.66 & 5.33 & 36 & 59.0 & 19 & 31.1 & 3 & 4.9 & 3 & 4.9 \\
\hline 20 & 84 & 21.3 & 9.45 & 6.34 & 38 & 45.2 & 34 & 40.5 & 5 & 6.0 & 7 & 8.3 \\
\hline 21 & 116 & 29.4 & 9.47 & 6.13 & 51 & 44.0 & 52 & 44.8 & 7 & 6.0 & 6 & 5.2 \\
\hline 22 & 79 & 20.0 & 9.84 & 5.77 & 31 & 39.2 & 35 & 44.3 & 8 & 10.1 & 5 & 6.3 \\
\hline $23+$ & 55 & 13.9 & 9.38 & 5.43 & 24 & 43.6 & 24 & 43.6 & 4 & 7.3 & 3 & 5.5 \\
\hline \multicolumn{13}{|l|}{ Disposable income } \\
\hline \multirow{5}{*}{$\begin{array}{l}<R 1000 \\
R 1001-R 2000 \\
\text { R2 001-R3000 } \\
\text { R3001-R4000 } \\
\text { R4000+ }\end{array}$} & 114 & 24.2 & 7.39 & 5.37 & 66 & 57.9 & 42 & 36.8 & 1 & 0.9 & 5 & 4.4 \\
\hline & 137 & 29.0 & 9.53 & 6.1 & 60 & 43.8 & 59 & 43.1 & 6 & 4.4 & 12 & 8.8 \\
\hline & 96 & 20.3 & 10.26 & 6.03 & 39 & 40.6 & 39 & 40.6 & 11 & 11.5 & 7 & 7.3 \\
\hline & 72 & 15.3 & 9.67 & 6.04 & 31 & 43.1 & 31 & 43.1 & 6 & 8.3 & 4 & 5.6 \\
\hline & 53 & 11.2 & 11.21 & 6.26 & 15 & 28.3 & 28 & 52.8 & 6 & 11.3 & 4 & 7.5 \\
\hline \multicolumn{13}{|l|}{ Source of income } \\
\hline \multirow{3}{*}{$\begin{array}{l}\text { Parents } \\
\text { Part-time job } \\
\text { Bursary } \\
\end{array}$} & 364 & 82.2 & 9.31 & 6.05 & 165 & 45.3 & 152 & 41.8 & 22 & 6.0 & 25 & 6.9 \\
\hline & 67 & 15.1 & 9.09 & 5.06 & 31 & 46.3 & 27 & 40.3 & 7 & 10.4 & 2 & 3.0 \\
\hline & 12 & 2.7 & 6.42 & 1.88 & 7 & 58.3 & 5 & 41.7 & 0 & 0.0 & 0 & 0.0 \\
\hline \multicolumn{13}{|l|}{ Living environment } \\
\hline \multirow{4}{*}{$\begin{array}{l}\text { Parents } \\
\text { Student res } \\
\text { Alone } \\
\text { House/apartment }\end{array}$} & 62 & 13.2 & 7.05 & 5.01 & 38 & 61.3 & 20 & 32.3 & 2 & 3.2 & 2 & 3.2 \\
\hline & 147 & 31.4 & 9.12 & 6.47 & 69 & 46.9 & 58 & 39.5 & 7 & 4.8 & 13 & 8.8 \\
\hline & 29 & 6.2 & 8.86 & 4.92 & 14 & 48.3 & 12 & 41.4 & 2 & 6.9 & 1 & 3.4 \\
\hline & 230 & 49.1 & 10.27 & 5.94 & 87 & 37.8 & 109 & 47.4 & 18 & 7.8 & 16 & 7.0 \\
\hline \multicolumn{13}{|l|}{ Race } \\
\hline \multirow{3}{*}{$\begin{array}{l}\text { White } \\
\text { Black } \\
\text { Coloured }\end{array}$} & 426 & 90.6 & 9.41 & 5.99 & 189 & 44.4 & 181 & 42.5 & 29 & 6.8 & 27 & 6.3 \\
\hline & 9 & 1.9 & 9.22 & 9.04 & 6 & 66.7 & 1 & 11.1 & 0 & 0.0 & 2 & 22.2 \\
\hline & 32 & 6.8 & 7.81 & 4.42 & 16 & 50.0 & 15 & 46.9 & 0 & 0.0 & 1 & 3.1 \\
\hline \multicolumn{13}{|l|}{ Graduate level } \\
\hline \multirow{7}{*}{$\begin{array}{l}1^{\text {st }} \text { year } \\
2^{\text {nd }} \text { year } \\
3^{\text {rd }} \text { year } \\
4^{\text {th }} \text { year/honours } \\
\text { Masters } \\
\text { Undergraduate } \\
\text { Postgraduate }\end{array}$} & 63 & 13.5 & 7.52 & 4.96 & 34 & 54.0 & 25 & 39.7 & 1 & 1.6 & 3 & 4.8 \\
\hline & 95 & 20.3 & 9.03 & 6.17 & 46 & 48.4 & 37 & 38.9 & 5 & 5.3 & 7 & 7.4 \\
\hline & 228 & 48.7 & 9.98 & 6.32 & 94 & 41.2 & 100 & 43.9 & 16 & 7.0 & 18 & 7.9 \\
\hline & 80 & 17.1 & 9.26 & 5.47 & 35 & 43.8 & 34 & 42.5 & 8 & 10.0 & 3 & 3.8 \\
\hline & 2 & 0.4 & 11 & 1.41 & 0 & 0.0 & 2 & 100 & 0 & 0.0 & 0 & 0.0 \\
\hline & 386 & 82.5 & 9.35 & 6.13 & 174 & 45.1 & 162 & 42.0 & 22 & 5.7 & 28 & 7.3 \\
\hline & 82 & 17.5 & 9.31 & 5.41 & 35 & 42.7 & 36 & 43.9 & 8 & 9.8 & 3 & 3.7 \\
\hline Religion & & & & & & & & & & & & \\
\hline Religious & 384 & 81.0 & 9.12 & 6.16 & 187 & 48.7 & 147 & 38.3 & 23 & 6.0 & 27 & 7.0 \\
\hline Non-religious & 90 & 19.0 & 10.36 & 5.29 & 26 & 28.9 & 52 & 57.8 & 7 & 7.8 & 5 & 5.6 \\
\hline Relationship status & & & & & & & & & & & & \\
\hline Single & 259 & 54.6 & 9.56 & 6.24 & 114 & 44.0 & 109 & 42.1 & 17 & 6.6 & 19 & 7.3 \\
\hline In a relationship & 215 & 45.4 & 9.11 & 5.74 & 99 & 46.0 & 90 & 41.9 & 13 & 6.0 & 13 & 6.0 \\
\hline
\end{tabular}

university students. Kypri et al. (2005) furthermore suggest that university students drink more than their non-student counterparts, reinforcing the argument that university students are a problematic group of individuals as far as drinking behaviour is concerned. In this sample more than half of participants (55.1\%) indicated drinking at hazardous levels and above, with 42 per cent exhibiting hazardous drinking behaviour followed by 6.3 per cent exhibiting harmful 
drinking patterns and a disconcerting 6.8 per cent reporting dependent levels of alcohol consumption.

Taking these preliminary results into account, it can be argued that respondents appear to drink in an unhealthy and dangerous manner which could lead to adverse physical, psychological and emotional consequences to both themselves and those around them. The student respondents are not isolated in their unhealthy drinking behaviour as a global pattern of similarly high levels of hazardous, harmful and binge drinking behaviour among university students is evident in the literature (Kypri et al. 2002; 2005; Kypri et al. 2009; Webb et al. 1996). Moreover, research at other South African universities suggests that students exhibit similar unhealthy and dangerous drinking patterns which classify their drinking behaviour as a public health concern (Mogotsi et al. 2014; Young and De Klerk 2008).

Even though excessive drinking is widespread among the sample population, only a small number of students were under the impression that they drink too much (7\%) or have a drinking problem (1\%). In addition, the vast majority of students (82\%) indicated that they would not find it hard to cut down or stop drinking in the near future. These findings indicate that even though students in the sample drink in a manner that is physically and psychologically harmful to themselves, they are of the opinion that their drinking is normal and non-problematic. It can therefore be posited that students at university assume that drinking in excess and in a harmful manner is socially acceptable and part of their university experience (i.e. normal).

\section{Socio-demographic differences}

\section{Gender and drinking behaviour}

Table 3 provides the results of the independent sample t-tests conducted to determine if differences exist between males and females with regard to drinking behaviour.

Table 3: Differences in drinking behaviour between males and females

\begin{tabular}{|l|c|c|c|c|c|}
\hline \multicolumn{1}{|c|}{ Hypotheses } & Df & t-value & Sig & Eta squared & Significant \\
\hline $\mathrm{H}_{1(\mathrm{~A}): \text { Frequency of consumption }}$ & 472 & 4.01 & 0.000 & 0.03 & Yes \\
\hline $\mathrm{H}_{1(\mathrm{~B}): \text { Level of consumption }}$ & 472 & 8.33 & 0.000 & 0.13 & Yes \\
\hline $\mathrm{H}_{1(\mathrm{C}): \text { Binge drinking }}$ & 472 & 7.63 & 0.000 & 0.11 & Yes \\
\hline $\mathrm{H}_{1(\mathrm{D}): \text { Hazardous drinking }}$ & 362.92 & 7.27 & 0.000 & 0.10 & Yes \\
\hline
\end{tabular}

From Table 3, it is evident that significant differences exist between males and females with regard to drinking behaviour. It appears that male university students $(\mathrm{M}=2.49, \mathrm{SD}=0.81)$ consume alcohol more frequently than female university students $(M=2.19, S D=0.78)$, thus 
supporting $\mathrm{H}_{1(\mathrm{~A})}$. However, the magnitude of the difference in the mean scores was very small (eta squared=0.03). Furthermore, male university students $(M=6.29, S D=2.4)$ were found to consume higher levels of alcohol than female university students ( $M=4.5, S D=2.23)$, providing

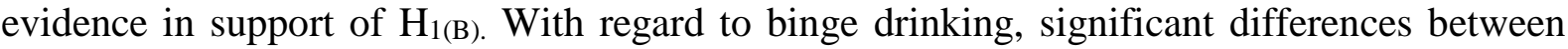
male $(\mathrm{M}=1.85, \mathrm{SD}=0.97)$ and female $(\mathrm{M}=1.17, \mathrm{SD}=0.93)$ university students are evident. $\mathrm{A}$ total of 32 per cent of male university students indicated binge drinking patterns while only 9 per cent of female university students reported binge drinking, thus supporting $\mathrm{H}_{1(\mathrm{C}) \text {. }}$

To determine if male and female university students differ in terms of hazardous, harmful and dependent drinking patterns, an independent sample t-test using the total AUDIT score was conducted. The analysis reported that statistically significant differences do in fact exist between males $(M=11.67, S D=6.47)$ and females $(M=7.67, S D=5.05)$. In total, 71 per cent of male university students and 43.4 per cent of female university students exhibited hazardous levels of drinking and above, providing support for $\mathrm{H}_{1(\mathrm{D})}$. Altogether, male university students reported higher levels of hazardous, harmful and dependent drinking patterns compared to female university students. These findings correspond with existing literature on gender differences signifying that male university students consume more alcohol and do so in a more dangerous manner than female university students (El Ansari et al. 2013; Global Status Report on Alcohol and Health 2011; Peltzer et al. 2011; Wilsnack et al. 2009).

A possible explanation for these findings is the biological differences that exist between males and females with regard to alcohol absorption and metabolisation. Contrary to popular belief, males and females of the same height and weight do not experience the same effects from consuming identical amounts of alcohol. Females tend to have less body water than males of similar height and weight, so that females achieve higher concentrations of alcohol in the blood after drinking equivalent amounts of alcohol. Females also have less of a gastric or stomach enzyme called dehydrogenase that metabolises or breaks down alcohol before it enters the bloodstream. Because of this, females can absorb up to 30 per cent more alcohol into their bloodstream than males of the same height and weight who drink the same amount of alcohol (Frezza et al. 1990; Taylor et al. 1996). Females are also on average shorter and weigh less than males, further concentrating alcohol in their blood. Therefore, females are much more vulnerable than males to the adverse consequences of alcohol use. Resultantly, it can be argued that males and females consume alcohol in vastly different manners and will be affected differently due to biological differences.

However, Wilsnack et al. (2000) argue that biological differences alone cannot be used to explain gender differences in drinking behaviour, and they propose a collaborative approach 
that combines socio-cultural and biological factors in attempting to understand gender differences in drinking behaviour. According to the collaborative approach, biological gender differences are used to establish socially acceptable mannerisms with regard to alcohol. In other words, because males can biologically drink more than females, it has become socially more acceptable for males to drink more often and in larger quantities than females (Wilsnack et al. 2000). Hence, it is postulated that socio-cultural and biological factors interact to further explain gender differences in drinking behaviour among South African university students.

\section{Age and drinking behaviour}

Table 4 provides the results of the one-way ANOVAs that were conducted to analyse whether drinking behaviour among university students differs across different age groups.

Table 4: Differences in drinking behaviour between age groups

\begin{tabular}{|l|c|c|c|c|c|}
\hline \multicolumn{1}{|c|}{ Hypotheses } & Df & F value & Sig & Eta squared & Significant \\
\hline $\mathrm{H}_{2(\mathrm{~A}): \text { Frequency of consumption }}$ & 4,390 & 2.62 & 0.075 & $\mathrm{~N} / \mathrm{A}$ & No \\
\hline $\mathrm{H}_{2(\mathrm{~B}): \text { Level of consumption }}$ & 4,390 & 2.26 & 0.062 & $\mathrm{~N} / \mathrm{A}$ & No \\
\hline $\mathrm{H}_{2(\mathrm{C}): \text { Binge drinking }}$ & 4,390 & 2.05 & 0.086 & $\mathrm{~N} / \mathrm{A}$ & No \\
\hline $\mathrm{H}_{2(\mathrm{D}): \text { Hazardous drinking }}$ & 4,390 & 1.38 & 0.240 & $\mathrm{~N} / \mathrm{A}$ & No \\
\hline
\end{tabular}

No statistically significant differences were observed between the age of university students and alcohol consumption behaviour. Thus, the research suggests that university students' drinking behaviour is not dependent on their age, leading to $\mathrm{H}_{2(\mathrm{~A})}$ through $\mathrm{H}_{2(\mathrm{D})}$ not being supported. A possible explanation for this contradictory finding is that individuals start studying at different ages and students form part of different friendship and boarding-house groups, which can influence their drinking behaviour (e.g. a first-year student can have older, working friends that could lead to more conservative drinking behaviour).

\section{Disposable income and drinking behaviour}

The drinking behaviour of university students with differential levels of disposable income was compared using a one-way ANOVA to determine if distinct differences exist, the results of which are exhibited in Table 5. For the purpose of the analysis, participants were divided into five groups based on their level of disposable income per month (Group 1: R1 000 or less; Group 2: R1 001 to R2 000; Group 3: R2 001 to R3 000; Group 4: R3 001 to R4 000; Group 5: R4 000 and above). 
Table 5: Differences in drinking behaviour between levels of disposable income

\begin{tabular}{|l|c|c|c|c|c|}
\hline \multicolumn{1}{|c|}{ Hypotheses } & Df & F value & Sig & Eta squared & Significant \\
\hline $\mathrm{H}_{3(\mathrm{~A}): \text { Frequency of consumption }}$ & 4,467 & 4.73 & 0.001 & 0.04 & Yes \\
\hline $\mathrm{H}_{3(\mathrm{~B}): \text { Level of consumption }}$ & 4,467 & 5.44 & 0.000 & 0.04 & Yes \\
\hline $\mathrm{H}_{3(\mathrm{C}): \text { Binge drinking }}$ & 4,467 & 3.98 & 0.003 & 0.03 & Yes \\
\hline $\mathrm{H}_{3(\mathrm{D}): \text { Hazardous drinking }}$ & 4,467 & 5.05 & 0.001 & 0.04 & Yes \\
\hline
\end{tabular}

Statistically significant differences were observed between the frequency of alcohol consumption and the level of disposable income. Post-hoc comparisons reported that the mean score for Group 1 (M=2.08, $\mathrm{SD}=0.83)$ was significantly lower than Group $3(\mathrm{M}=2.43$, $\mathrm{SD}=0.78)$, Group $4(\mathrm{M}=2.49, \mathrm{SD}=0.69)$ and Group $5(\mathrm{M}=2.51, \mathrm{SD}=0.80)$, suggesting that higher levels of disposable income are related to more frequent alcohol consumption among university students, thus supporting $\mathrm{H}_{3(\mathrm{~A})}$. Furthermore, the results suggest that the level of alcohol consumption, as measured by the AUDIT consumption subscale, for Group $1(\mathrm{M}=4.43$, $\mathrm{SD}=2.21$ ) was significantly lower than for Group $2(\mathrm{M}=5.31, \mathrm{SD}=2.46)$, Group 3 ( $\mathrm{M}=5.60$, $\mathrm{SD}=2.45)$, Group $4(\mathrm{M}=5.43, \mathrm{SD}=2.51)$ and Group $5(\mathrm{M}=6.08, \mathrm{SD}=2.57)$. The results support

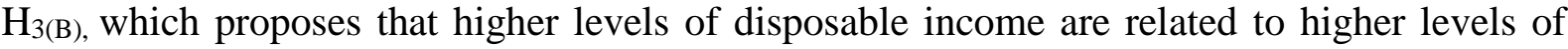
alcohol consumption. Significant differences were also observed between the level of disposable income of university students and binge drinking behaviour, with Group $1(\mathrm{M}=1.17$, $\mathrm{SD}=0.85)$ exhibiting a significantly lower binge drinking score than Group $3(\mathrm{M}=1.56$, $\mathrm{SD}=1.04)$ and Group $5(\mathrm{M}=1.74, \mathrm{SD}=1.02)$. The observed difference indicates that students with higher levels of disposable income are more likely to engage in binge drinking behaviour, providing support for $\mathrm{H}_{3(\mathrm{C}) \text {. }}$

Lastly, significant differences exist between the total AUDIT score and the level of disposable income. Post-hoc comparisons indicated that the mean score for Group 1 (M=7.39, $\mathrm{SD}=5.37)$ was significantly lower than for Group $2(\mathrm{M}=9.53, \mathrm{SD}=6.10)$, Group $3(\mathrm{M}=10.26$, $\mathrm{SD}=6.03)$ and Group $5(\mathrm{M}=11.21, \mathrm{SD}=6.26)$, suggesting that higher levels of disposable income are related to more dangerous drinking patterns, thus lending support to $\mathrm{H}_{3(\mathrm{D})}$. The mean differences between the groups in all four analyses were small to moderate, with effect sizes ranging from 0.03 to 0.04 . These findings are consistent with previous research attesting to the positive relationship between drinking behaviour and disposable income (Keyes and Hasin 2008; Obot 2006), suggesting that students with higher levels of disposable income are more prone to alcohol abuse and alcohol-related problems. Taking a closer look at the data it can be suggested that lower levels of disposable income might also be a buffer against alcohol abuse, as students receiving less than R1 000 per month report lowest levels of alcohol consumption and healthiest drinking patterns. The most likely explanation is that students receiving less than 
R1 000 disposable income per month do not have sufficient resources to spend on alcohol as other, more important, expenditures take priority.

\section{Preferred type of beverage and drinking behaviour}

To measure the impact of the specific beverage consumed on the drinking behaviour of university students, respondents were divided into four groups based on the alcoholic beverage they most often consume (beer, ciders, wine, and spirits). The results of the one-way ANOVAs are provided in Table 6.

Table 6: Differences in drinking behaviour between preferred types of beverage

\begin{tabular}{|l|c|c|c|c|c|}
\hline \multicolumn{1}{|c|}{ Hypotheses } & Df & F value & Sig & Eta squared & Significant \\
\hline $\mathrm{H}_{4(\mathrm{~A}): \text { Frequency of consumption }}$ & 3,450 & 11.33 & 0.000 & 0.07 & Yes \\
\hline $\mathrm{H}_{4(\mathrm{~B}): \text { Level of consumption }}$ & 3,450 & 31.50 & 0.000 & 0.17 & Yes \\
\hline $\mathrm{H}_{4(\mathrm{C}): \text { Binge drinking }}$ & 3,450 & 30.64 & 0.000 & 0.17 & Yes \\
\hline $\mathrm{H}_{4(\mathrm{D}): \text { Hazardous drinking }}$ & 3,450 & 28.80 & 0.000 & 0.16 & Yes \\
\hline
\end{tabular}

With regard to frequency of alcohol consumption all alcoholic beverages significantly differed from each other, with the exception of wine $(\mathrm{M}=2.30, \mathrm{SD}=0.82)$ and spirits $(\mathrm{M}=2.28, \mathrm{SD}=0.80)$. Overall, beer $(\mathrm{M}=2.60, \mathrm{SD}=0.74)$ had the highest frequency of consumption followed by wine $(\mathrm{M}=2.30,0.82)$, spirits $(\mathrm{M}=2.28, \mathrm{SD}=0.80)$ and lastly ciders $(\mathrm{M}=1.92, \mathrm{SD}=0.74)$. Spirits was not the alcoholic beverage associated with the highest frequency of consumption as initially expected, resulting in a lack of support for $\mathrm{H}_{4(\mathrm{~A})}$. The results also suggest that the levels of alcohol consumption among university students differ significantly between the four types of alcoholic beverages, with beer associated with the highest level of consumption followed by spirits, wine and lastly ciders. Post-hoc comparisons indicated that the mean score for beer $(\mathrm{M}=6.56, \mathrm{SD}=2.20)$ was significantly higher than that for ciders $(\mathrm{M}=4.11, \mathrm{SD}=2.19)$ and wine $(\mathrm{M}=4.33, \mathrm{SD}=2.15)$. Furthermore, ciders $(\mathrm{M}=4.11, \mathrm{SD}=2.19)$ and wine $(\mathrm{M}=4.33, \mathrm{SD}=2.15)$ indicated significantly lower consumption levels compared to spirits ( $M=5.97, S D=2.49$ ). Spirits was not the type of beverage with the highest level of consumption as initially anticipated; in fact, it was beer that had the highest level of consumption, resulting in $\mathrm{H}_{4(\mathrm{~B})}$ not being supported.

Likewise, statistically significant differences were observed between the types of alcoholic beverages and binge drinking behaviour, with beer drinkers once again exhibiting the highest score followed by spirits, ciders, and lastly wine consumers. Post-hoc testing indicated that the mean score for beer $(\mathrm{M}=1.97, \mathrm{SD}=0.86)$ was significantly higher than for ciders $(\mathrm{M}=1.07, \mathrm{SD}=0.93)$ and wine $(\mathrm{M}=1.06, \mathrm{SD}=0.89)$. Furthermore, ciders $(\mathrm{M}=1.07, \mathrm{SD}=0.93)$ and 
wine ( $M=1.06, S D=0.89)$ were again considerably lower than spirits $(M=1.77, S D=1.00)$. Even though significant differences were reported between the types of alcoholic beverages, $\mathrm{H}_{4(\mathrm{C})}$ was not supported based on the fact that beer was the type of beverage associated with the highest binge drinking score, with spirits in a close second position. Lastly, significant differences were observed between the total AUDIT score of university students and preferred type of alcoholic beverage, with beer drinkers exhibiting the highest AUDIT score followed by spirits, wine and ciders consumers. The mean score for beer $(M=12.54, S D=6.37)$ was significantly higher than the mean scores for both ciders $(M=6.46, S D=4.85)$ and wine $(\mathrm{M}=7.40, \mathrm{SD}=4.80)$. Additionally, ciders $(\mathrm{M}=6.46, \mathrm{SD}=4.85)$ and wine $(\mathrm{M}=7.40, \mathrm{SD}=4.80)$ once again reported lower scores than spirits $(\mathrm{M}=10.82, \mathrm{SD}=5.83)$. Beer, and not spirits as hypothesised, was associated with the most dangerous drinking patterns, leading to $\mathrm{H}_{4(\mathrm{D})}$ not being accepted.

In conclusion, beer was reported to be the type of alcoholic beverage related to the highest level of alcohol consumption, the highest rate of binge drinking, the highest frequency of alcohol consumption, and the most dangerous patterns of drinking, leading to $\mathrm{H}_{4(\mathrm{~A})}, \mathrm{H}_{4(\mathrm{~B})}, \mathrm{H}_{4(\mathrm{C})}$ and $\mathrm{H}_{4(\mathrm{D})}$ not being supported. The difference in mean scores between the four groups in the frequency analysis was moderate, with the remaining three analyses examining level of consumption, binge drinking, and hazardous drinking reporting large effect sizes. Although these findings contradict the expected outcome, a literature review conducted by Engs and Hanson (1990) regarding the drinking behaviour of university students revealed that beer was in fact the preferred beverage among university students, thus providing merit to the present findings.

Although beer was associated with the highest level and frequency of alcohol consumption, it is interesting to note that beer was not the preferred beverage in any of the social situations assessed in the present study. Although beer is not the beverage of choice among students in most situations, it can be argued that those respondents who do prefer to drink beer, tend to drink more frequently and in larger quantities than students who prefer other types of alcoholic beverages. Therefore, it can be postulated that students who mostly consume beer are the most prone to alcohol-related problems due to their drinking behaviour, and that the specific beverages consumed by university students can potentially be used as a method to identify individuals who are more prone to problematic drinking.

\section{CONCLUSIONS, RECOMMENDATIONS AND LIMITATIONS}

Evidence from this study suggests that university students drink in a manner that could be 
physically, psychologically and emotionally harmful to themselves and to those around them, and that their drinking behaviour is characterised by significant socio-demographic differences. Socio-demographic information, together with an understanding of student drinking behaviour could serve as valuable insights and a platform for the development of action steps towards addressing these harmful behaviours.

South African universities' responsible drinking campaigns could reflect the sociodemographic and drinking behaviour findings of this study to influence drinking behaviour more significantly with a message that students can identify with. Designing, and more importantly targeting, an alcohol education and prevention campaign that takes these findings into account could be much more effective at achieving much needed behaviour change among university students with regard to their drinking behaviour.

For example, designing a campaign that depicts primarily male students drinking hard liquor (i.e. spirits) in a social setting (e.g. bar or club) late in the evening while highlighting the dangers of excessive alcohol consumption or poor decision-making under the influence of alcohol (e.g. deciding to drink and drive) will more likely resonate with this cohort of consumers, and be a more effective approach than traditional messages encouraging abstinence. The campaign can take a solution-focused approach to drinking and driving by encouraging students to for example utilise ride sharing services as a means of safe transportation to and from parties, bars and clubs. Social marketing campaigns can also leverage the social drinking motives exhibited by university students (Du Preez et al. 2016) and emphasise the potential social embarrassment accompanying excessive drinking. Campaigns should include message elements to increase self-efficacy and empower students to make informed choices about alcohol consumption through knowledge and an optimal level of control and support.

Although students report disconcertingly high levels of hazardous, harmful and dependent drinking patterns, most student respondents regard their drinking as neither problematic nor harmful and see it as part of the university experience. It can be postulated that a prevention strategy focused on promoting alcohol abstinence and educating on the harmful effects of alcohol abuse will not have the desired effect, as students see drinking as part of 'normal student life' and are oblivious or ignorant of the harmful and hazardous nature of their drinking behaviour. Instead of using the traditional education and prevention strategy of only educating students about the dangers and negative consequences of drinking, a revised approach is advocated (Beall et al. 2012; Wymer 2011). Campaigns can also emphasise knowledge of the physical and psychological effects of alcohol consumption, reinforce the positive effects of abstinence from alcohol and offer different ways of socialising (Eastman 2002). Alternatively, 
campaigns can follow the controversial yet effective approach of promoting moderate and more responsible alcohol consumption while simultaneously discouraging excessive and irresponsible alcohol use (see for example the initiative by Educ'alcool, a non-profit organisation operating in Canada, in Hubert 2006).

These approaches should focus on a supportive and nurturing empowerment message that encourages much needed behaviour change and could draw from inter-disciplinary knowledge fields (e.g. Psychology, Sociology, Consumer Psychology, Marketing and Advertising) that tap into what is collectively known about inter alia: socialisation theory, empowerment and disempowerment, self-efficacy, motivation and needs, behaviour and attitude change theory, message framing, persuasive communication and targeting. Future research could fruitfully explore these avenues.

The findings have implications for three stakeholders. They may assist public health authorities and higher education management to design and implement more effective alcohol policies, alcohol abuse prevention and education programmes targeted at this group of individuals. For academia, the study can serve to stimulate additional research into the drinking behaviour of university students in South Africa in order to better understand this cohort of consumers. Given the complexity of drinking behaviour, future research should include interdisciplinary perspectives, and broaden the scope of social marketing research. For example, an analysis of message content and the ability of messages to increase knowledge, and selfefficacy, and to influence attitudes toward drinking and drinking behaviour could provide more directive findings for message choice.

Notwithstanding the useful contributions of this study, some methodological limitations should be noted namely convenience sampling, size of the sample and the use of self-report measurement instruments. Further to this, the cohort sample cannot be regarded as representative of all South African university students and a national study may significantly contribute to the understanding of South African university students' drinking behaviour. Future research should address these limitations and respond to the call for inter-disciplinary research that will assist all stakeholders to understand and curb harmful student drinking behaviour.

\section{REFERENCES}

Ahlström, S., K. Bloomfield and R. Knibbe. 2001. Gender differences in drinking patterns in nine European countries: Descriptive findings. Substance Abuse 22(1): 69-85.

Allen, J. P., R. Z. Litten, J. B. Fertig and T. Babor. 1997. A review of research on the Alcohol Use Disorders Identification Test (AUDIT). Alcoholism: Clinical and Experimental Research 21(4): 613-619. 
Andersson, C., K. O. Johnsson, M. Berglund and A. Ojehagen. 2007. Alcohol involvement in Swedish university freshmen related to gender, age, serious relationship and family history of alcohol problems. Alcohol and Alcoholism 42(5): 448-455.

Babor, T. F., J. C. Higgins-Biddle, J. B. Saunders and M. G. Monteiro. 2001. The Alcohol Use Disorders Identification Test: Guidelines for use in primary care. http://whqlibdoc.who.int/hq/2001/ who_msd_msb_01.6a.pdf (accessed 20 February 2014).

Barefoot, J. C., M. Grønbæk, J. R. Feaganes, R. S. McPherson, R. B. Williams and I. C. Siegler. 2002. Alcoholic beverage preference, diet, and health habits in the UNC Alumni Heart Study. The American Journal of Clinical Nutrition 76(2): 466-472.

Beall, T., J. Wayman, H. D’Agostino, A. Angie Liang and C. Perellis. 2012. Social marketing at a critical turning point. Journal of Social Marketing 2(2): 103-117.

Bewick, B. M., B. Mulhern, M. Barkham, K. Trusler, A. J. Hill and W. B. Stiles. 2008. Changes in undergraduate student alcohol consumption as they progress through university. BMC Public Health 8(1): 163.

Casswell, S., M. Pledger and R. Hooper. 2003. Socioeconomic status and drinking patterns in young adults. Addiction 98(5): 601-610.

Cohen, J. 1988. Statistical power analysis for the behavioral sciences. Hillsdale, NJ: Lawrence Erlbaum Associates.

Corbin, W. R., E. L. Vaughan and K. Fromme. 2008. Ethnic differences and the closing of the sex gap in alcohol use among college-bound students. Psychology of Addictive Behaviors 22(2): 240-248.

Du Preez, R., C. D. Pentz and B. W. Lategan. 2016. Why students drink: A study of South African university students' drinking behaviour. South African Journal of Higher Education 30(2): 73-93.

Eastman, P. 2002. The student perspective on college drinking. http://www.collegedrinkingprevention .gov/supportingresearch/student1.aspx (accessed 16 March 2016).

El Ansari, W., R. Sebena and C. Stock. 2013. Socio-demographic correlates of six indicators of alcohol consumption: Survey findings of students across seven universities in England, Wales and Northern Ireland. Archives of Public Health 71(1): 29-41.

Elgar, F. J., C. Roberts, N. Parry-Langdon and W. Boyce. 2005. Income inequality and alcohol use: A multilevel analysis of drinking and drunkenness in adolescents in 34 countries. The European Journal of Public Health 15(3): 245-250.

Engs, R. C. and D. J. Hanson. 1990. Gender differences in drinking patterns and problems among college students: A review of the literature. Journal of Alcohol and Drug Education 35(2): 36-47.

Fleming, M. F., K. L. Barry and R. MacDonald. 1991. The alcohol use disorders identification test (AUDIT) in a college sample. International Journal of Addictions 26(11): 1173-1185.

Frezza, M., C. Di Padova, G. Pozzato, M. Terpin, E. Baraona and C. S. Lieber. 1990. High blood alcohol levels in women: The role of decreased gastric alcohol dehydrogenase activity and first-pass metabolism. New England Journal of Medicine 322(2): 95-99.

Gaziano, J. M., C. H. Hennekens, S. L. Godfried, H. D. Sesso, R. J. Glynn, J. L. Breslow and J. E. Buring. 1999. Type of alcoholic beverage and risk of myocardial infarction. The American Journal of Cardiology 83(1): 52-57.

Germishuys, G. 2015. Zero alcohol limit: How you'll be hit. http://www.wheels24.co.za/News/SA-0alcohol-limit-How-youll-be-hit-20150204 (accessed 9 July 2015).

Gill, J. S. 2002. Reported levels of alcohol consumption and binge drinking within the UK undergraduate student population over the last 25 years. Alcohol and Alcoholism 37(2): 109-120.

Global Status Report on Alcohol and Health. 2011. http://www.who.int/substance_abuse/publications/ global_alcohol_report/msbgsruprofiles.pdf (accessed 15 December 2013).

Global Status Report on Alcohol and Health. 2014. http://www.who.int/substance_abuse/publications/ global_alcohol_report/msb_gsr_2014_1.pdf?ua=1 (accessed 25 June 2014). 
Granville-Chapman, J. E., K. Yu and P. D. White. 2001. A follow-up survey of alcohol consumption and knowledge in medical students. Alcohol and Alcoholism 36(6): 540-543.

Hingson, R. W., W. Zha and E. R. Weitzman. 2009. Magnitude of and trends in alcohol-related mortality and morbidity among US college students ages 18-24, 1998-2005. Journal of Studies on Alcohol and Drugs Supplement 16: 12-20.

Holmila, M. and K. Raitasalo. 2005. Gender differences in drinking: Why do they still exist? Addiction 100(12): 1763-1769.

Hubert, S. 2006. Moderating effect. Marketing Magazine 111(14): 17-20.

Jensen, M. K., A. T. Andersen, T. I. Sørensen, U. Becker, T. Thorsen and M. Grønbæk. 2002. Alcoholic beverage preference and risk of becoming a heavy drinker. Epidemiology 13(2):127-132.

Jernigan, D. H. 2001. Global Status Report: Alcohol and young people. http://whqlibdoc.who.int/ hq/2001/who_msd_msb_01.1.pdf (accessed 9 July 2015).

Johnston, L. D., P. M. O’Malley, J. G. Bachman and J. E. Schulenberg. 2009. Monitoring the future: National survey results on drug use, 1975-2008. Volume II: College students and adults ages 1950. Bethesda, MD: National Institute on Drug Abuse.

Keyes, K. M. and D. S. Hasin. 2008. Socio-economic status and problem alcohol use: The positive relationship between income and the DSM-IV alcohol abuse diagnosis. Addiction 103(7): 11201130.

Klatsky, A. L., M. A. Armstrong and H. Kipp. 1990. Correlates of alcoholic beverage preference: Traits of persons who choose wine, liquor or beer. British Journal of Addiction 85(10): 1279-1289.

Kypri, K., M. Cronin and C. S. Wright. 2005. Do university students drink more hazardously than their non-student peers? Addiction 100(5): 713-714.

Kypri, K., J. D. Langley, R. McGee, J. B. Saunders and S. Williams. 2002. High prevalence, persistent hazardous drinking among New Zealand tertiary students. Alcohol and Alcoholism 37(5): 457464.

Kypri, K., M. J. Paschall, J. Langley, J. Baxter, M. Cashell-Smith and B. Bourdeau. 2009. Drinking and alcohol- related harm among New Zealand university students: Findings from a National Web-Based Survey. Alcoholism: Clinical and Experimental Research 33(2): 307-314.

Lategan, B. W. 2015. Drinking behaviour, alcohol outcome expectancies, and drinking motives of South African university students: A consumer behaviour perspective. Unpublished master's thesis, University of Stellenbosch, South Africa.

Maccoby, E. and J. Martin. 1983. Socialization in the context of the family: Parent-child interaction. In Handbook of child psychology, socialization, personality, and social development, ed. E. M. Heteringhton and P. H. Mussen, 1-101. New York, NY: Wiley.

McShane, K. E. and J. A. Cunningham. 2003. The role of relevancy in normative feedback for university students’ drinking patterns. Addictive Behaviors 28(8):1523-1528.

Mogotsi, M., K. Nel, W. Basson and C. Tebele. 2014. Alcohol use by students at an emerging university in South Africa. Journal of Sociology and Social Anthropology 5(2): 187-195.

Nunnally, J. C. and I. H. Bernstein. 1994. Psychometric theory. 3rd Edition. New York, NY: McGrawHill.

Obot, I. S. 2006. Alcohol use and related problems in sub-Saharan Africa. African Journal of Drug and Alcohol Studies 5(1): 17-26.

O’Hare, T. and M. V. Sherrer. 1999. Validating the alcohol use disorder identification test with college first-offenders. Journal of Substance Abuse Treatment 17(1): 113-119.

Opperman, C. 2010. Investigating the marketing of South African wine amongst the emerging black market of South Africa. Unpublished master's thesis, University of Stellenbosch, South Africa.

Paiva, F. S., R. R. Bastos and T. M. Ronzani. 2012 Parenting styles and alcohol consumption among Brazilian adolescents. Journal of Health Psychology 17(7): 1011-1021. 
Peltzer, K. and S. Ramlagan. 2009. Alcohol use trends in South Africa. Journal of Social Sciences 18(1): $1-12$.

Peltzer, K., A. Davids and P. Njuho. 2011. Alcohol use and problem drinking in South Africa: Findings from a national population-based survey. African Journal of Psychiatry 14(1): 30-37.

Peltzer, K. K., P. P. Naidoo, G. G. Matseke and K. K. Zuma. 2011. Screening and brief interventions for hazardous and harmful alcohol use among patients with active tuberculosis attending primary care clinics in South Africa: A cluster randomized controlled trial protocol. BMC Public Health 11(1): 1-9.

Powell, P. A., V. B. Faden and S. Wing. 2007. The Surgeon General's call to action to prevent and reduce underage drinking. http://www.camy.org/factsheets/sheets/alcohol_advertising promotion/Call_To_Action.pdf (accessed 12 July 2014).

Reinert, D. F. and J. P. Allen. 2007. The alcohol use disorders identification test: An update of research findings. Alcoholism: Clinical and Experimental Research 31(2): 185-199.

Saunders, J. B., O. G. Aasland, T. F. Babor, J. R. De la Fuente and M. Grant. 1993. Development of the alcohol use disorders identification test (AUDIT): WHO collaborative project on early detection of persons with harmful alcohol consumption II. Addiction 88(6): 791-804.

Schneider, M., R. Norman, C. Parry, D. Bradshaw, A. Pluddemann. 2007. Estimating the burden of disease attributable to alcohol use in South Africa in 2000. South African Medical Journal 97(8): 664-672.

Schulenberg, J. E. and J. L. Maggs. 2002. A developmental perspective on alcohol use and heavy drinking during adolescence and the transition to young adulthood. Journal of Studies on Alcohol Supplement 14: 54-70.

Shields, A. L., K. Guttmannova and J. C. Caruso. 2004. An examination of the factor structure of the Alcohol Use Disorders Identification Test in two high-risk samples. Substance Use \& Misuse 39(7): 1161-1182.

Siegel, M. B., T. S. Naimi, J. L. Cremeens and D. E. Nelson. 2011. Alcoholic beverage preferences and associated drinking patterns and risk behaviors among high school youth. American Journal of Preventive Medicine 40(4): 419-426.

Slutske, W. S., E. E. Hunt-Carter, R. E. Nabors-Oberg, K. J. Sher, K. K. Bucholz, P. A. F. Madden, A. Anokhin and A. C. Heath. 2004. Do college students drink more than their non-college-attending peers? Evidence from a population-based longitudinal female twin study. Journal of Abnormal Psychology 113(4): 530-540.

Solomon, M. 2013. Adults earning less than what students spend. http://www.ru.ac.za/ studentaffairs/latestnews/adultsearninglessthanwhatstudentsspend.html (accessed 10 January 2015).

South African Press Association. 2013. Cabinet approves bill banning alcohol ads. http://www.bizcommunity.com/Article/196/12/100595.html (accessed 9 July 2015).

Taylor, J. L., N. Dolhert, L. Friedman, M. Mumenthaler and J. A. Yesavage. 1996. Alcohol elimination and simulator performance of male and female aviators: A preliminary report. Aviation, Space, and Environmental Medicine 67(5): 407-413.

The ICD-10 Classification of Mental and Behavioural Disorders. 1992. http://www.who.int/ classifications/icd/en/bluebook.pdf (accessed 16 January 2017).

Van Heerden, M. S., A. T. Grimsrud, S. Seedat, L. Myer, D. R. Williams and D. J. Stein. 2009. Patterns of substance use in South Africa: Results from the South African Stress and Health study. South African Medical Journal 99(5): 358-366.

Wallace, J. M., J. G. Bachman, P. M. O’Malley, J. E. Schulenberg, S. M. Cooper and L. D. Johnston. 2003. Gender and ethnic differences in smoking, drinking and illicit drug use among American 8th, 10th and 12th grade students, 1976-2000. Addiction 98(2): 225-234.

Webb, E., C. H. Ashton, P. Kelly and F. Kamali. 1996. Alcohol and drug use in UK university students. 
The Lancet 348(9032): 922-925.

Wilsnack, R. W., N. D. Vogeltanz, S. C. Wilsnack and T. R. Harris. 2000. Gender differences in alcohol consumption and adverse drinking consequences: Cross - cultural patterns. Addiction 95(2): 251265.

Wilsnack, R. W., S. C. Wilsnack, A. F. Kristjanson, N. D. Vogeltanz-Holm and G. Gmel. 2009. Gender and alcohol consumption: Patterns from the multinational GENACIS project. Addiction 104(9): 1487-1500.

Wymer, W. 2011. Developing more effective social marketing strategies. Journal of Social Marketing 1(1): 17-31.

Young, C. and V. de Klerk. 2008. Patterns of alcohol use on a South African university campus: Findings of two annual drinking surveys. African Journal of Drug and Alcohol Studies 7(2): 101-112.

Zailckas, K. 2006. Smashed: Story of a drunken girlhood. London: Penguin Books. 